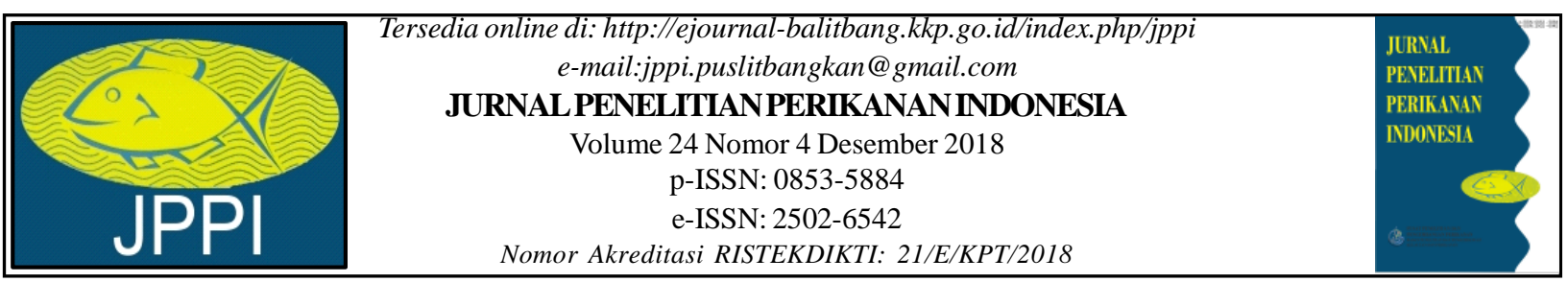

\title{
PARAMETER POPULASI HIU MACAN (Galeocerdo cuvier Peron \& Lesuer, 1822) DI PERAIRAN SELATAN NUSA TENGGARA BARAT
}

\section{POPULATION PARAMETERS TIGER SHARK (Galeocerdo cuvier Peron \& Lesuer, 1822) IN THE SOUTH OF WEST NUSA TENGGARA WATERS}

\author{
Umi Chodrijah*1, Agus Arifin Sentosa ${ }^{2}$ dan Prihatiningsih ${ }^{1}$ \\ ${ }^{1}$ Balai Riset Perikanan Laut, Cibinong, Bogor, Jl. Raya Bogor KM. 47 Nanggewer Mekar, Jawa Barat, Indonesia \\ ${ }^{2}$ Balai Riset Pemulihan Sumber Daya Ikan, Jalan Cilalawi No. 01 Jatiluhur, Purwakarta, Jawa Barat, 41152, Indonesia \\ Teregistrasi I tanggal: 11 Mei 2018; Diterima setelah perbaikan tanggal: 31 Januari 2019; \\ Disetujui terbit tanggal: 31 Januari 2019
}

\begin{abstract}
ABSTRAK
Hiu macan atau tiger shark (Galeocerdo cuvier Peron \& Lesuer, 1822) banyak tertangkap di perairan Samudera Hindia. Status konservasinya masuk dalam Daftar merah IUCN dan hampir terancam (NT). Tujuan penelitian adalah untuk mendapatkan informasi parameter populasi hiu macan di perairan Samudera Hindia bagian Selatan Nusa Tenggara Barat. Penelitian dilakukan di tempat pendaratan ikan Tanjung Luar, Lombok Timur pada bulan Januari sampai dengan Desember 2016 menggunakan metode survei. Hasil penelitian terhadap 808 ekor ikan contoh menunjukkan bahwa kisaran panjang total untuk hiu macan (Galeocerdo cuvier) antara 116 - 400 cmTL. Perbandingan kelamin ikan hiu macan jantan dan betina dalam keadaan tidak seimbang, dengan jumlah betina lebih besar. Estimasi panjang asimtotik $\left(L_{\infty}\right)$ sebesar $420 \mathrm{~cm} T L$ dengan laju pertumbuhan $(K)$ sebesar 0,260/tahun, laju kematian total $(Z)$ sebesar 1,10/tahun, laju kematian alamiah (M) sebesar 0,35/tahun serta laju kematian akibat penangkapan (F) sebesar 0,75/tahun. Estimasi laju eksploitasi sudah berada pada penangkapan yang berlebih $(E=0,68)$ oleh karena itu perlu dilakukan tindakan pengelolaan agar pemanfaatannya tetap lestari.
\end{abstract}

\section{Kata Kunci: Parameter; populasi; hiu macan; Galeocerdo cuvie; Nusa Tenggara Barat}

\begin{abstract}
Tiger sharks (Galeocerdo cuvier Peron \& Lesuer, 1822) were widely held in the depths of the Indian Ocean. Its conservation status was on the IUCN Red List and was near threatened (NT). The purpose of this study was to obtain the parameters of growth in the South off West Nusa Tenggara waters. The study was conducted at Tanjung Luar landing site, East Lombok in January until December 2016. The observation included total length and sex with visual measurement and observation in the field. The results of the study showed the number of 808 individues that the total length range for tiger shark (Galeocerdo cuvier) caught in Indian Ocean waters landed on Tanjung Luar was distributed on a size between 116-400 cmTL with an average length of $242.8 \mathrm{~cm} T \mathrm{~L}$ and a mode at $240 \mathrm{cmTL}$. The sex ratio of male and female tiger sharks was in an unbalanced state, with larger females. Estimation of asymptotic length $\left(L_{\infty}\right)$ of $420 \mathrm{cmTL}$ with growth rate $(K) 0.260$ / year, total mortality rate $(Z) 1.10$ / year, natural mortality rate $(M) 0.35$ / year and mortality rate due to arrest $(F) 0.75$ / year. Estimation of the rate of exploitation has led to overfishing $(E=0.68)$ therefore it was necessary to take regulatory and management measures to ensure sustainable utilization.
\end{abstract}

Keywords: Population; parameter; tiger shark; West Nusa Tenggara

Korespondensi penulis:

umi_chodriyah@yahoo.co.id 


\section{PENDAHULUAN}

Hiu macan atau tiger shark (Galeocerdo cuvier Peron \& Lesuer, 1822) merupakan hiu dari famili Carcharhinidae yang status konservasinya menurut International Union for the Conservation of Nature and Natural Resources (IUCN) adalah hampir terancam (NT) (White et al., 2006). Hiu secara umum sangat rentan terhadap tekanan penangkapan berlebih (Musick et al., 2000). Hal ini dikarenakan beberapa sifat biologi hiu yaitu siklus hidupnya yang panjang, pertumbuhan dan kematangan kelaminnya yang lambat serta fekunditasnya yang rendah (Compagno, 1984; Last \& Stevens, 1994). Oleh sebab itu, monitoring terhadap status populasi hiu macan dan hiu lainnya perlu dilakukan sehingga pengelolaan dapat dilakukan secara berkelanjutan.

Untuk mendasari pengelolaan hiu, maka diperlukan masukan dari hasil penelitian, termasuk salah satunya studi tentang parameter populasi. Penelitian ini bertujuan untuk mengetahui laju pertumbuhan, laju kematian dan tingkat pemanfaatan hiu macan (Galeocerdo cuvier) di perairan Samudera Hindia Selatan Nusa Tenggara Barat. Informasi yang dihasilkan diharapkan dapat digunakan sebagai bahan masukan untuk pengelolaan dan konservasi sumberdaya hiu agar dapat dimanfaatkan secara berkelanjutan.

\section{BAHAN DAN METODE}

Penelitian ini dilaksanakan di perairan Nusa Tenggara Barat dengan tempat sampling di TPI Tanjung Luar, Lombok Timur, Nusa Tenggara Barat pada Januari sampai Desember 2016. Daerah penangkapan ikan hiu macan disajikan pada Gambar 1. Identifikasi jenis dilakukan dengan menggunakan beberapa referensi menurut Last \& Stevens (1994), Tarp \& Kailola, (1984) dan White et al. (2006). Gambar morfologi ikan hiu macan disajikan pada Gambar 2.

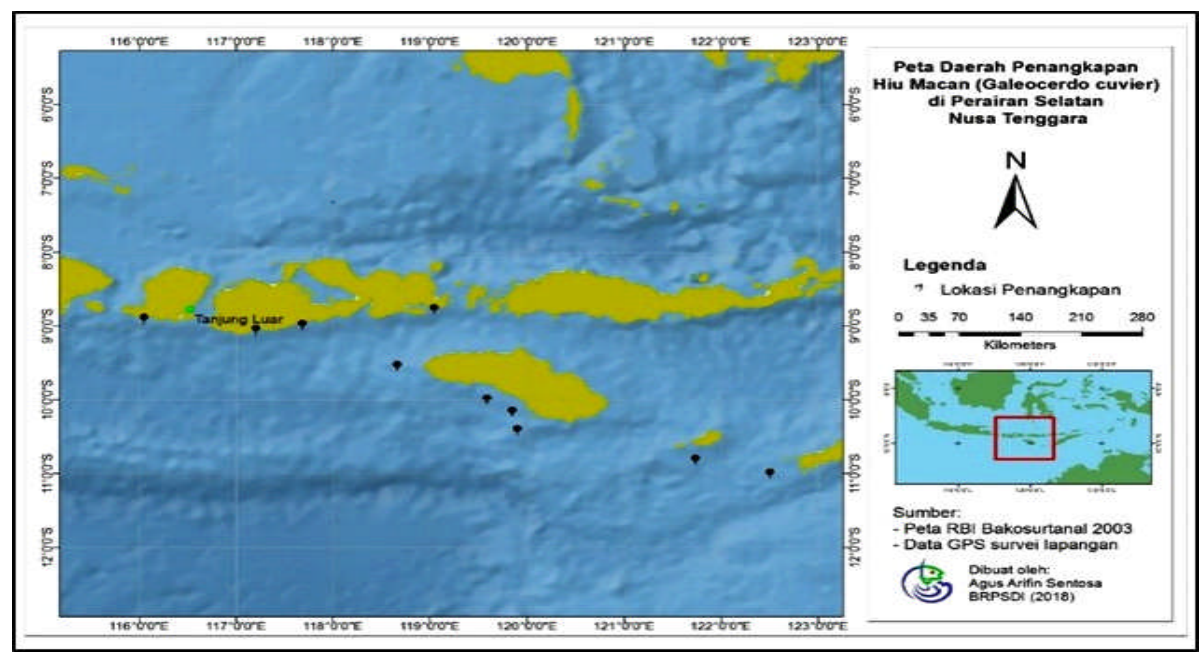

Gambar 1. Daerah penangkapan hiu macan di perairan Selatan Nusa Tenggara Barat.

Figure 1. Fishing ground of tiger shark in the South off West Nusa Tenggara Waters.

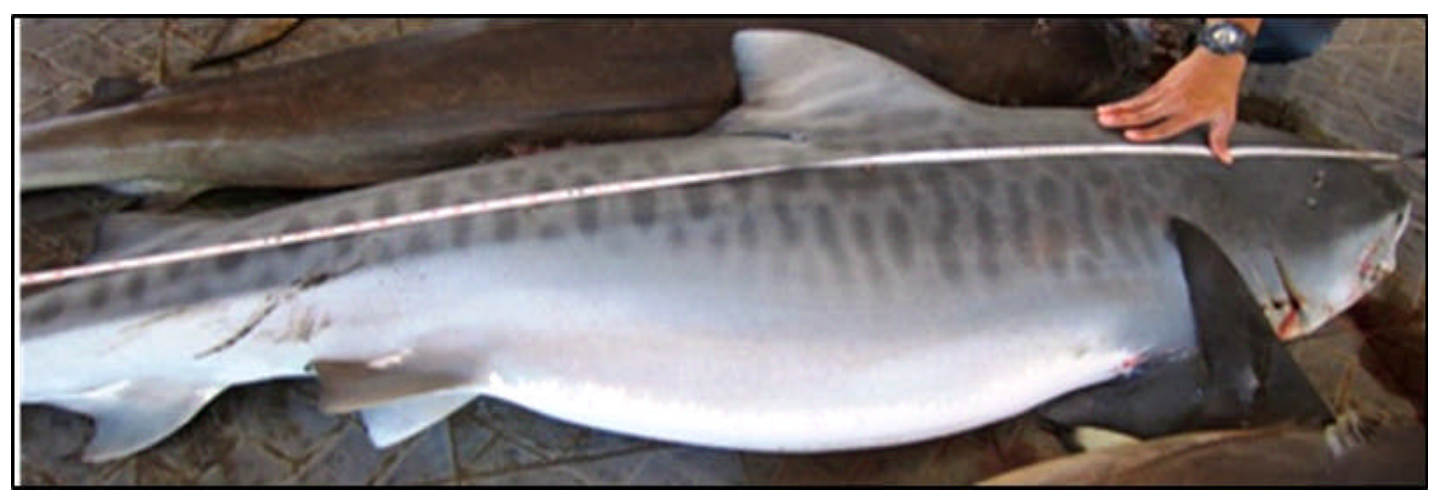

Gambar 2. Morpologi Hiu macan (Galeocerdo cuvier).

Figure 2. Tiger shark morphologic. 
Pengumpulan sampel ikan hiu macan (Galeocerdo cuvier) secara berkesinambungan sebanyak 808 ekor dilakukan oleh enumerator terlatih. Karakter biologi individu hiu macan yang diukur antara lain panjang total (TL) (dalam $\mathrm{cm}$ ) dan jenis kelamin. Penentuan jenis kelamin dilakukan berdasarkan ciri sepasang klasper (untuk hiu jantan), yaitu modifikasi dari perpanjangan kedua sirip perut hiu jantan yang digunakan sebagai alat kopulasi. Keseimbangan nisbah kelamin dianalisis dengan uji Chi-kuadrat (Steel \& Torrie, 1993) yaitu:

$$
X^{2}=\sum_{i=1}^{k} \frac{(f o-f n)^{2}}{f n}
$$

dimana :

$X^{2}=$ Chi Square

$\mathrm{Fo}=$ frekuensi yang diobservasi

$\mathrm{Fn}=$ frekuensi yang diharapkan

Pertumbuhan ikan hiu macan dianalisis berdasarkan persamaan pertumbuhan von Bertalanffy (Sparre \& Venema,1992):

$$
L t=\operatorname{Loo}(1-\exp (-k(t-t o)))
$$

Di mana Lt adalah panjang total ikan hiu macan saat umur $t, \mathrm{~L}_{\infty}$ adalah panjang total maksimum secara teoritis (panjang total asimptotik), $\mathrm{K}$ adalah laju pertumbuhan dan $t_{0}$ adalah umur teoritis saat panjang total ikan hiu macan nol. Panjang total asimptotik $\left(\mathrm{L}_{\infty}\right)$ dan laju pertumbuhan $(\mathrm{K})$ diestimasi dengan program ELEFAN I dalam program FISAT II berdasarkan pergeseran modus ukuran panjang total ikan hiu macan pada tiap bulan (Gayanilo et al., 2005). Umur pada saat sebelum memasuki perikanan (to) diduga berdasarkan persamaan Pauly (1983):

$$
\log \left(-t_{o}\right)=0,3922-0,2752 \log \left(L_{\infty}\right)-1.038 \log (K)
$$

Laju mortalitas meliputi laju mortalitas total (Z), laju mortalitas alami (M) dan laju mortalitas penangkapan (F). Laju mortalitas total ( $\mathrm{Z}$ ) diduga dengan metode kurva konversi hasil tangkapan dengan panjang (length converted catch curve) (Sparre \&
Venema,1992). Pendugaan laju mortalitas alami (M) menggunakan persamaan Pauly et al.(1984) dengan penambahan nilai temperatur rata-rata $(T)$ sebesar 28 ${ }^{\circ} \mathrm{C}$ sebagai berikut:

$$
\begin{aligned}
\log (M)= & -0,0066-0,279{ }^{*} \log \left(L_{\infty}\right)+0,6543 \\
& { }^{*} \log (K)+0,4634{ }^{*} \log (T) \ldots \ldots \ldots \ldots \ldots \ldots(4)
\end{aligned}
$$

dimana:

$$
\begin{aligned}
& \mathrm{L}_{\infty}=\text { panjang asimptotik }(\mathrm{cmTL}) \\
& \mathrm{K}=\text { kecepatan pertumbuhan } \\
& \mathrm{T}=\text { rataan suhu lingkungan perairan }=28^{\circ} \mathrm{C}
\end{aligned}
$$

Laju mortalitas penangkapan dan laju eksploitasi diduga dengan persamaan Sparre \& Venema (1992) yaitu :

$\mathrm{F}=(\mathrm{Z}-\mathrm{M})$

Laju eksploitasi (E) dihitung menggunakan persamaan:

$E=F / Z$

\section{HASIL DAN BAHASAN \\ Hasil}

Struktur ukuran panjang hiu macan jantan terdistribusi pada ukuran 124 - $400 \mathrm{~cm} T L$ dengan ratarata 244,54 cmTL dan hiu macan betina terdistribusi pada ukuran 116 - $398 \mathrm{cmTL}$ dengan rata-rata 241,51 $\mathrm{cmTL}$. Hiu macan betina dan jantan didominasi ukuran $240 \mathrm{cmTL}$ (Gambar 3).

Sedangkan hasil pengukuran panjang bulanan, terlihat bahwa hiu macan didominasi pada ukuran 200$250 \mathrm{cmTL}$ (Gambar 4).

Berdasarkan hasil analisis, diperoleh perbandingan kelamin antara hiu macan jantan dan betina adalah $1,0: 1,28$. Berdasarkan uji Chi-Square diperoleh hasil $X^{2}=11,89 ; X^{2}$ tabel $(0,05)=3,84 ; X^{2}$ tabel $(0,01)=6,64$ yang berarti perbandingan jenis jantan dan betina dalam keadaan tidak seimbang. Nisbah kelamin bulanan ikan hiu macan disajikan pada Gambar 5. 


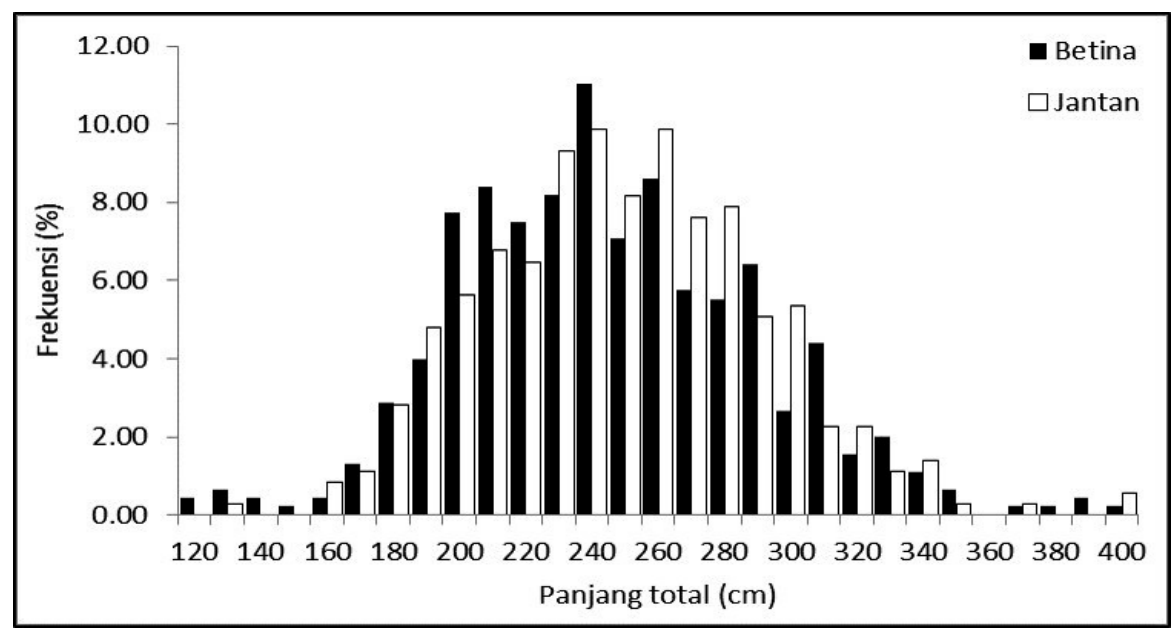

Gambar 3. Distribusi frekuensi panjang total ikan hiu macan (Galeocerdo cuvier) betina dan jantan di perairan Selatan Nusa Tenggara Barat.

Figure 3. Total length distribution of tiger shark female and male in the South off West Nusa Tenggara Waters.

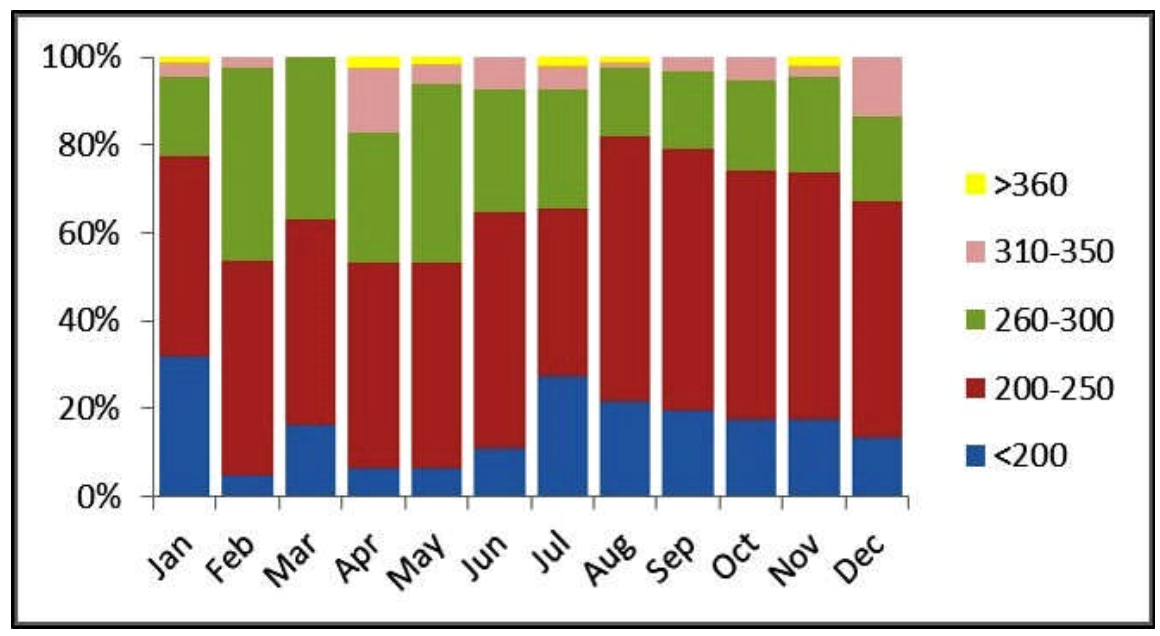

Gambar 4. Sebaran ukuran panjang total bulanan ikan hiu macan di perairan Selatan Nusa Tenggara Barat. Figure 4. Monthly distribution of the total length of tiger shark (Galeocerdo cuvier) in the South off West Nusa Tenggara Waters.

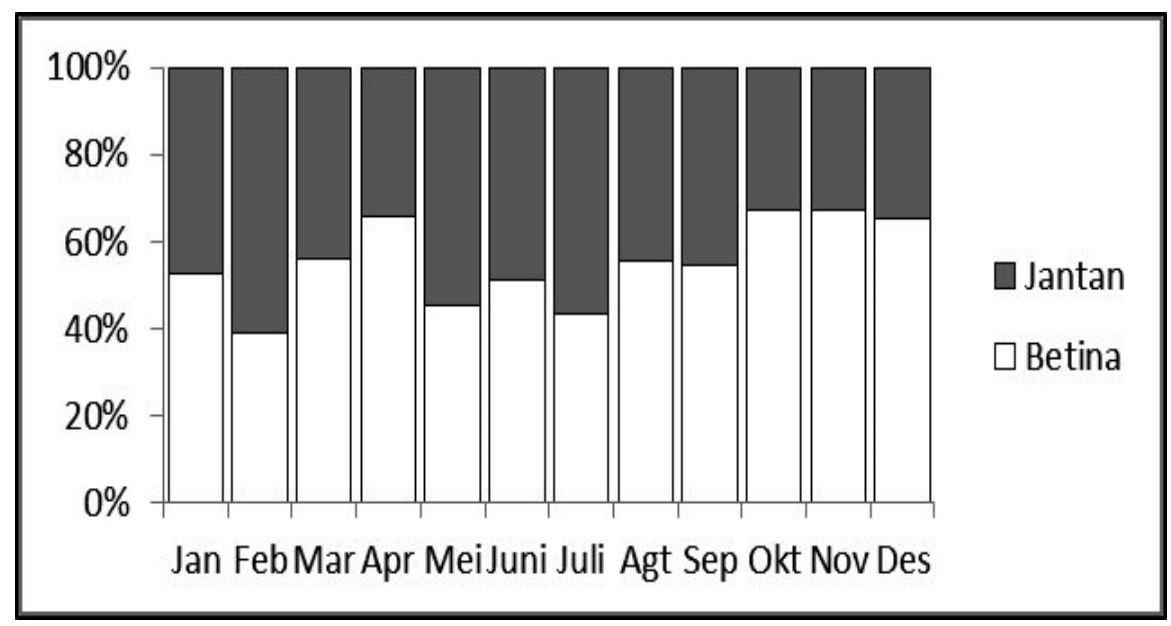

Gambar 5. Perbandingan kelamin hiu macan bulanan di perairan Selatan Nusa Tenggara Barat.

Figure 5. Monthly sex ratio of tiger shark in the South off West Nusa Tenggara Waters. 
Data sebaran frekuensi panjang total hiu macan setiap bulan disajikan pada Gambar 6. Berdasarkan hasil analisa diperoleh panjang total asimptotik $\left(\mathrm{L}_{\infty}\right)$ sebesar $420 \mathrm{cmTL}$ dengan laju pertumbuhan (K) sebesar 0,260 pertahun.

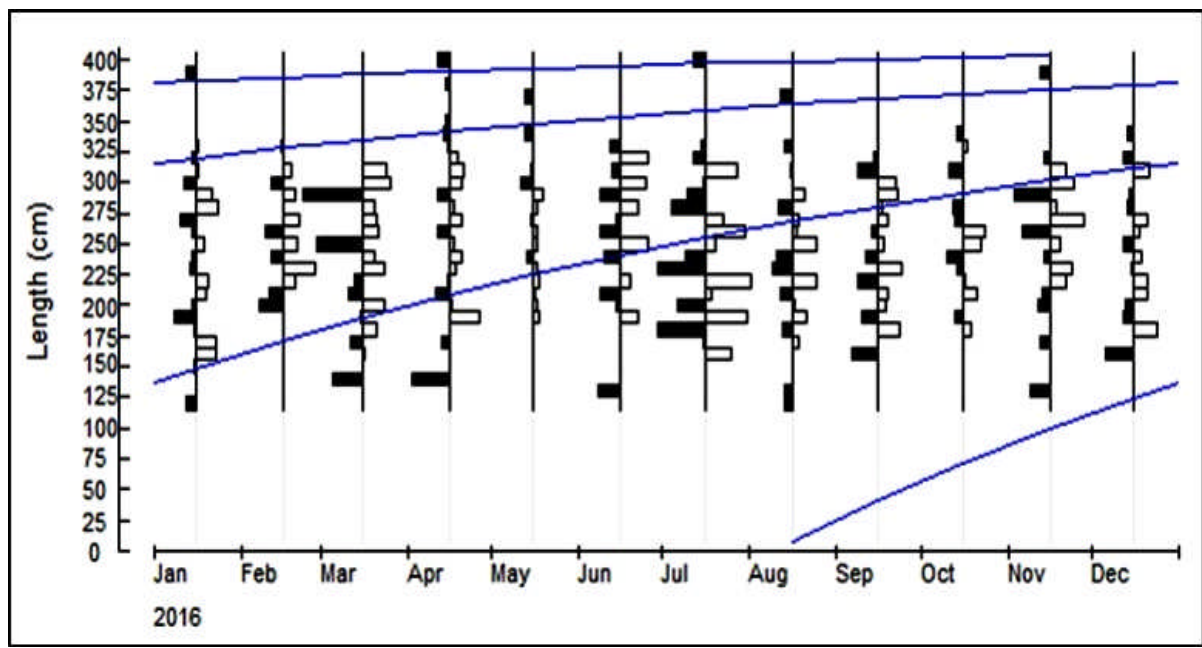

Gambar 6. Kurva pertumbuhan hiu macan di perairan Selatan Nusa Tenggara Barat.

Figure 6. Growth curve of tiger shark in the South off West Nusa Tenggara Waters.

Berdasarkan pergeseran struktur ukuran panjang total hiu macan di perairan Selatan Nusa Tenggara Barat pada Januari hingga Desember 2016, diperoleh panjang total asimptotik $\left(\mathrm{TL}_{\infty}\right)$ adalah $420 \mathrm{cmTL}$ dan koefisien pertumbuhan $(\mathrm{K})$ hiu macan adalah 0,260 per tahun dan umur pada saat panjang sama dengan $0\left(\mathrm{t}_{\mathrm{o}}\right)$ adalah $-0,019$ tahun sehingga diperoleh persamaan Von Bertalanffy hiu macan yaitu $L(t)=420\left(1-e^{\wedge}(-0,260(t+0,01899))\right.$. Hiu macan mencapai ukuran maksimum diduga pada umur 11,5 tahun atau sekitar 138 bulan (Gambar 8).
Hasil analisa laju kematian menunjukkan bahwa laju kematian alamiah (M) hiu macan sebesar 0,35 per tahun, laju kematian akibat penangkapan (F) sebesar 0,75 per tahun, serta laju kematian total ( $Z$ ) sebesar 1,10 per tahun. Kurva hasil tangkapan yang dilinierkan berdasarkan panjang total dengan kemiringan (slope) sebagai nilai $Z$ disajikan pada Gambar 7. Pada Gambar 8 disajikan kurva pertumbuhan von Bertalanffy dari hiu macan berdasarkan umur dan panjang total hiu macan.

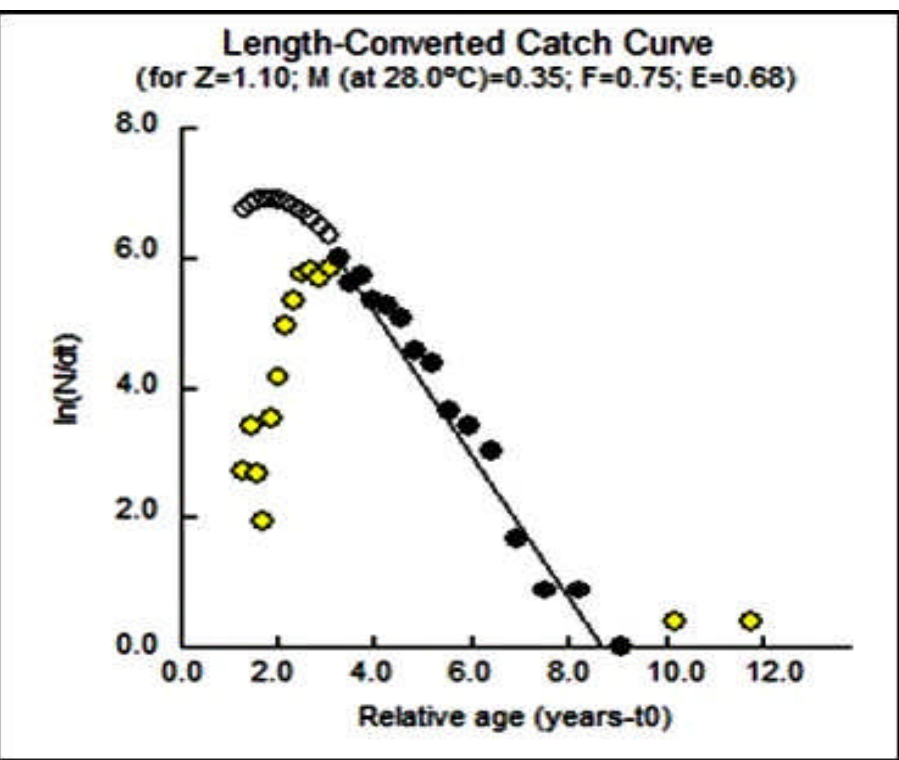

Gambar 7. Estimasi nilai Z sebagai slope kurva konversi hasil tangkapan ikan hiu macan di perairan Selatan Nusa Tenggara Barat.

Figure 7. The estimated value of total mortality $(Z)$ as a slope of length converted catch curve of tiger shark in the South off West Nusa Tenggara Waters. 


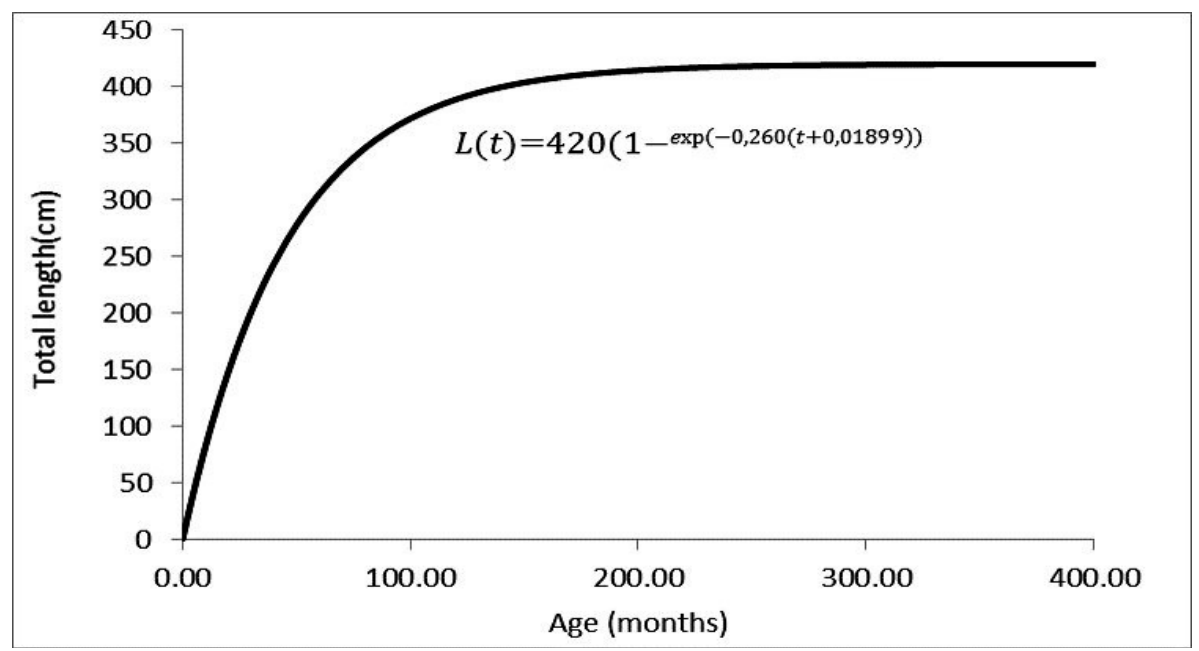

Gambar 8. Kurva pertumbuhan von Bertalanffy hiu macan berdasarkan nilai $\mathrm{K}=0,260 /$ th, $\mathrm{L}_{\infty}=420 \mathrm{cmTL}$. Figure 8. Von Bertalanffy growth curve of tiger shark in term of $K=0,260 / y r$ and $L_{\infty}=420 \mathrm{cmTL}$.

\section{Bahasan}

Berdasarkan hasil penelitian, hiu macan (Galeocerdo cuvier) yang tertangkap mempunyai kisaran panjang total antara 116 - $398 \mathrm{cmTL}$, ratarata $241,51 \mathrm{~cm}$ untuk betina dan $124-400 \mathrm{cmTL}$, rata-rata $244,54 \mathrm{~cm}$ untuk jantan. Menurut Chodrijah \& Faizah (2015) ukuran hiu macan jantan dan betina di perairan yang sama berkisar antara $130-396 \mathrm{cmTL}$. Penelitian yang dilakukan oleh Heitheus, (2001) menemukan hiu macan di perairan Australia Barat berkisar antara 148-407 cmTL. Meyer et al. (2014) menemukan ukuran maksimum hiu macan adalah 380 $\mathrm{cmTL}$ dan $450 \mathrm{~cm} T L$ dan sedikit yang mencapai 550 $\mathrm{cmTL}$. Perbedaan kisaran ukuran hiu macan yang tertangkap tersebut diduga karena adanya perbedaan selektivitas alat tangkap yang digunakan, ruaya dan daerah penangkapan (Sentosa et al., 2016). Menurut Lappalainen et al. (2016) bahwa tekanan penangkapan yang tinggi dan selektivitas alat tangkap yang rendah akan menyebabkan ukuran ikan tertangkap lebih kecil dan mempengaruhi ukuran matang gonadnya.

Berdasarkan nilai kisaran panjang tersebut, diperoleh hanya $13,8 \%$ jantan matang kelamin dan $14,5 \%$ betina yang matang gonad. Keadaan ini tidak mendukung bagi kelestarian spesies hiu macan dikarenakan ikan yang tertangkap adalah ikan muda dan belum memiliki kesempatan melahirkan sekali dalam siklus hidupnya (King, 2010). Hiu macan jantan mencapai matang kelamin pada ukuran 285 - 310 cmTL dan betina pada ukuran $287-345 \mathrm{cmTL}$ (Clark \& van Schmidt, 1965; Whitney \& Crow, 2007).

Perbandingan kelamin antara hiu betina dan jantan adalah $1: 0,78$ yang berarti berada dalam keadaan tidak seimbang. Hasil penelitian ini seiring dengan penelitian Meyer et al. (2014) yang menyatakan perbandingan hiu macan di Hawaii tidak seimbang dengan didominasi oleh individu betina namun hasil penelitian ini berbeda dengan penelitian Jaquemet et al. (2012) di perairan Samudera Hindia Bagian Barat serta Chodrijah \& Faizah (2015) di perairan Samudera Hindia Selatan Nusa Tenggara Barat yang menyatakan bahwa nisbah kelamin jantan dan betina seimbang. Perbedaan nisbah kelamin pada hiu macan diduga dipengaruhi oleh lokasi, oseanografi dan metode penangkapan. Main et al. (1996) menyatakan bahwa individu betina mendiami daerah dimana sumber makanan tersedia. Sementara Sims et al. (2005) menyatakan bahwa individu jantan cenderung berenang lebih aktif untuk mencari betina, sedangkan betina hanya bisa tinggal di tempat persembunyian.

Rasio kelamin berhubungan dengan jumlah ikan yang dihasilkan pada generasi berikutnya dan sebagai kontrol ukuran populasi (Effendie, 2002). Perbandingan jantan dan betina yang tidak seimbang akan meningkatkan kerentanan hiu macan di alam jika diekploitasi secara berlebihan mengancam keberlangsungan proses reproduksi suatu spesies ikan di suatu perairan. Hal ini dikarenakan dalam suatu populasi individu jantan akan berkompetisi untuk mendapatkan pasangan dalam bereproduksi (Dharmadi et al., 2007).

Data frekuensi panjang merupakan salah satu data yang dapat digunakan untuk menduga parameter pertumbuhan dari suatu spesies ikan (Sparre \& Venema, 1992). Panjang total asimptotik $\left(\mathrm{L}_{\infty}\right)$ dan laju pertumbuhan (K) hiu macan masing-masing sebesar $420 \mathrm{cmTL}$ dan 0,260 per tahun. 
Nilai K berpengaruh terhadap metabolik ikan atau udang yang merupakan suatu fungsi temperatur. Beverton \& Holt (1957) dalam Saputra (2009) menyatakan bahwa parameter kurva pertumbuhan (K) berkaitan dengan umur ikan, karena $K$ menggambarkan waktu yang diperlukan untuk mencapai $L_{\infty}$ dan umur yang panjang berkaitan dengan mortalitas. Pada umumnya ikan yang memiliki nilai $\mathrm{K}$ tinggi mempunyai $\mathrm{M}$ yang besar dan spesies dengan nilai $\mathrm{K}$ rendah mempunyai mortalitas yang rendah. Ikan yang tumbuh lambat (K rendah) akan cepat punah jika mortalitasnya tinggi.

Tabel 1. Panjang asimtotik dan laju pertumbuhan $(K)$ ikan hiu macan di beberapa lokasi perairan. Table 1. Asymptotic length $\left(L_{\infty}\right)$ and growth rate $(K)$ of Tiger shark in some location areas.

\begin{tabular}{lccl}
\hline Lokasi / Location & $\mathbf{L} \infty \mathbf{( c m})$ & $\mathbf{K}$ (tahun / year) & Penulis / Author \\
\hline Hawai & 406 & 0,310 & Meyer et al. (2014) \\
Australia & 403 & 0,080 & Holmes, B.J. (2015) \\
South Africa & 400 & 0,202 & Wintner \& Dudle (2000) \\
North-west Atlantic (USA) & 326 & 0,283 & Kneebone et al. (2008) \\
Nusa Tenggara Barat, Indonesia & 420 & 0,260 & Penelitian ini (2018) \\
\hline
\end{tabular}

Nilai panjang asimptotik dari hasil penelitian ini lebih besar jika dibandingkan dengan hasil penelitian di wilayah perairan lainnya. (Tabel 1). Cailliet et al. (1986) dan Goldman, (2005) dalam Holmes et al. (2015), menyatakan bahwa pertumbuhan elasmobranch dipengaruhi oleh beberapa faktor lingkungan seperti makanan, temperatur dan cahaya. Selanjutnya Wirsing et al. (2006) menyatakan bahwa perbedaan lingkungan dapat mempengaruhi kecepatan pertumbuhan. Tiews et al. (1970) dalam Sudrajad \& Nugroho (1983) berpendapat bahwa perbedaan kecepatan pertumbuhan spesies yang sama pada perairan yang berbeda antara lain disebabkan oleh kondisi lingkungan.

Berdasarkan hasil analisis, nilai mortalitas alami dari ikan hiu macan, $M=0,35$ per tahun dan mortalitas penangkapan $\mathrm{F}=0,75$ per tahun maka diperoleh nilai tingkat eksploitasi $E=0,68$. Tingkat eksploitasi hiu macan (Galeocerdo cuvier) di perairan Nusa Tenggara Barat ini lebih tinggi dari nilai laju ekspolitasi yang optimal $(E=0,5)$. Pauly et al. (1984) menyebutkan bahwa nilai laju eksploitasi yang rasional dan lestari di suatu perairan berada pada nilai $E<0,5$ atau paling tinggi pada nilai $E=0,5$. Tingkat eksploitasi ikan hiu macan terindikasi dalam kondisi lebih tangkap (over fishing), sehingga perlu adanya pengaturan kuota tangkap dan pengelolaan agar pemanfaatannya tetap lestari.

Keragaman upaya penangkapan setiap tahunnya akan mempengaruhi variasi mortalitas karena penangkapan $(F)$. Nilai $F$ menunjukkan seberapa besar dan meningkatnya tekanan penangkapan (fishing pressure) terhadap stok ikan di suatu perairan (Suman \& Boer, 2005). Menurut Pauly et al. (1984) nilai mortalitas alami (M) dari suatu jenis ikan tidak terlalu besar, biasanya nilainya dianggap tetap dari tahun ke tahun. Hal ini menyebabkan mortalitas total (Z) dari tahun ke tahun lebih dominan ditentukan oleh mortalitas karena penangkapan ( $F$ ) dibandingkan dengan mortalitas alami (M). Laju kematian total dipengaruhi oleh kematian alami (M) dan kematian karena penangkapan (F). Kematian karena penangkapan $(F)$ hiu macan lebih tinggi dibandingkan tingkat kematian alami (M) menunjukkan bahwa populasi hiu macan telah dieksploitasi secara intensif oleh nelayan di perairan Selatan Nusa Tenggara Barat. Hiu macan merupakan salah satu spesies yang memiliki kerentanan tinggi dalam eksploitasi. Tidak hanya tekanan dari aktivitas penangkapan, tetapi juga karena karakteristik biologinya yang membutuhkan waktu lama untuk mencapai matang gonad dan tingkat rekruitmennya sangat rendah (Hazin et al., 2007). Selain itu juga, masa kehamilan hiu macan ini diperkirakan 15-16 bulan dan ukuran pada saat lahir yaitu 80 - 90 cmTL (Clark \& van Schmidt, 1965; Whitney \& Crow, 2007).

\section{KESIMPULAN DAN SARAN}

Struktur ukuran hiu macan di perairan Selatan Nusa Tenggara Barat yang didaratkan di Tanjung Luar berkisar antara 116-400 cmTL dengan rerata ukuran panjang adalah $242,85 \mathrm{~cm} T \mathrm{~L}$. serta didominasi oleh hiu macan betina. Hiu macan yang banyak tertangkap adalah kelompok hiu macan muda (kurang dari 250 $\mathrm{cmTL}$ ) yang belum matang kelamin sehingga populasinya rentan terhadap recruitment overfishing. Hiu macan mampu mencapai panjang asimptotis 420 cmTL dan laju pertumbuhan (K) sebesar 0,260/tahun. Laju kematian total (Z), laju kematian alamiah (M) dan laju kematian karena penangkapan $(F)$, masingmasing sebesar 1,10/tahun, 0,35/tahun dan 0,75/ tahun. Laju eksploitasi (E) hiu macan sebesar 0,68/ tahun menandakan eksploitasi terhadap spesies ini 
sudah tinggi sehingga perlu adanya pengurangan upaya agar pemanfaatannya tetap lestari.

Perlu ditingkatkan penelitian dan monitoring hasil tangkapan hiu macan yang didaratkan agar data statistik hiu macan dapat tercatat dengan baik sehingga dapat bermanfaat dalam pengelolaan perikanan hiu di Indonesia.

\section{PERSANTUNAN}

Tulisan ini merupakan bagian dari kegiatan "Penelitian karakteristik biologi perikanan, habitat sumber daya ikan dan potensi produksi sumberdaya perikanan di WPP 573 (Samudera Hindia Selatan Jawa dan Nusa Tenggara)" pada Balai Riset Perikanan Laut, Jakarta, Tahun Anggaran 2016. Penulis mengucapkan terima kasih kepada Najamudin (petugas enumerator) di TPI. Tanjungluar yang telah membantu dalam pengumpulan data selama penelitian.

\section{DAFTAR PUSTAKA}

Beverton, R. J. H., \& Holt, S. J. (1957). On the dynamics of exploited fish populations. Fishlnvest. U.K. Ministry of Agriculture, Food and Fisheries, London. 533p.

Cailliet, G. M., Radtke, R. L., \& Welden, B. A. (1986). Elasmobranch age determination and verification: a review. In Indo-Pacific Fish Biology: Proceedings of the Second International Conference on Indo-Pacific Fishes (Uyeno, T., Arai, R., Taniuchi, T. \& Matsura, K., eds), pp. 345-359. Tokyo: Ichthyological Society of Japan.

Compagno, L. J. V. (1984). Sharks of the world. An annotated and illustrated catalogue of shark species known to date. Food and Agricultural Organization. pp. 470-472. (125) Vol.4. Pt.250-655.

Clark \& van Schmidt. (1965). Shark of the Central Gulf coast of Florida. Marine Science Bulletin. 15, 13-83.

Chodrijah, U., \& Faizah, R. (2015). Sebaran ukuran dan rasio kelamin hiu macan (Galeocerdo cuvier) di Perairan Samudera Hindia Bagian Selatan Nusa Temggara Barat. Prosiding Simposium Hiu dan Pari di Indonesia. 121-126.

Dharmadi, Fahmi., \& Adrim, M. (2007). Distribusi frekuensi panjang, hubungan panjang tubuh, panjang klasper, dan nisbah kelamin cucut lanjaman (Carcharhinus falciformis). J. Lit. Perikan. Ind. 13(3), 243-253. http://dx.doi.org/ 10.15578/jppi.13.3.2007.243-254.
Effendie, M. I. (2002). Biologi perikanan (p. 163). Yayasan Pustaka Nusatama. Yogyakarta.

Gayanilo, F.C.Jr., Sparre, P., \& Pauly, D. (2005). FAOICLARM Stock Assessment Tools II (FiSAT II). Revised version. User's guide. FAO Computerized Information Series (Fisheries). No. 8, Revised version. Rome, FAO, 168 p.

Goldman,K.J. (2005). Age and growth of elasmobranch fishes. In Management Techniques for Elasmobranch Fisheries (Musick, J. A. \& Bonfil, R., eds), pp. 76-102. Rome: FAO.

Hazin, F.H.V., Oliveira, P.G.V., \& Macena, B.C.L. (2007). Aspects of the reproductive biology of the silky shark, Carcharhinus falciformis (Nardo, 1827), in the vicinity of archipelago of Saint Peter and Saint Paul, in the equatorial Atlantic Ocean. Col. Vol. Sci. Pap. ICCAT. 60(2), 648-651.

Heitheus, M. R. (2001). The biology of tiger sharks, Galeocerdo cuvier, in Shark Bay, Western Australia: sex ratio, size distribution, diet, and seasonal changes in catch rates. Environmental Biology of Fishes. 61, 25-36.

Holmes, B. J., Paddemors, V.M., Gutteridge, A.N., Geraghty, P.T., Chan, R.W.K., Tibbetts, I.R., \& Bennett, M.B. (2015). Age and growth of the tiger shark Galeocerdo cuvier off the east coast of Australia. Journal of Fish Biology, (87), 422-448.

Jaquemet, S., Smale, M.J., Blaison, A., Guyomard, D., \& Soria, M. (2012). First observation of a pregnant tiger shark (Galeocerdo cuvier) at Reunuion Island, Western Indian Ocean. J. Mar. Scie. 11(2), 205-207.

Last, P.R., \& J.D. Stevens. (1994). Sharks and rays of Australia (p. 513). CSIRO. Australia.

Lappalainen, A., Saks, L., Sustar, M., Heikinheimo, O., Jurgens, K., Kokkonen, E., Kurkilahti, M., Verliin, A., \& Vetemaa, M. (2016). Length at maturity as a potential indicator off is hing pressure effects on coastal pikeperch (Sander lucioperca) stocks in the northern Baltic Sea. Fisheries Research, 174, 47-57.

Kneebone J, Natanson L.J., Andrews A.H., \& Howell W.H. (2008). Using bomb radiocarbon analyses to validate age and growth estimates for the tiger shark, Galeocerdo cuvier in the Western North Atlantic. Mar. Bio. 154, 423-434. 
King, M. (2010). Fisheries biology, assessment and management, Second Edition (p. 381). Oxford, England: Blackwell Publising Ltd.

Meyer, C.G., O 'Malley, J.M., Papastamatiou, Y.P., Dale, J.J., Hutchinson, M.R., Anderson, J.M, Royer, M.A., \& Holland, K.N. (2014). Growth and maximum size of tiger shark (Galeocerdo cuvier) in Hawaii. PLoS ONE,9(1),e84799, doi:10.1371/ journal.pone.0084799.

Main, M.B., Weckerly, F.W., Bleich, V.C. (1996). Sexual segregation in ungulates: new directions for research. J. Mammal, 77, 449-461.

Musick, J.A., Burgess, G., Cailliet, G., Camhi, M., \& Fordham, S. (2000). Management of sharks and their relatives (Elasmobranchii). Fisheries, 25, 913.

Pauly, D., Ingles, J., \& Neal, R. (1984). Application to shrimp stocks of objective methods for the estimation of growth, mortality, and recruitment related parameters from length frequency data (ELEFAN I and II). In Penaeid Shrimp-Their Biology \& Management. Fishing News Book Limited. Farnham-Surrey-England. p. 220-234.

Sentosa, A.A., Widarmanto, N., Wiadnyana, N.N., \& Satria, F. (2016). Perbedaan hasil tangkapan hiu dari rawai hanyut dan rawai dasar yang berbasis di Tanjung Luar, Lombok. J.Lit.Perikan. Ind, 22(2), 105-114. http://dx.doi.org/10.15578/jppi.22.2.2016.105114.

Sims, D.W., Southall, E.J., Wearmouth, V.J., Hutchinson, N., Budd, G.C., \& Morrit, D. (2005). Refuging behaviour in the nursehound Scyliorhinus stellaris: preliminary evidence from acoustic telemetry. J Mar Biol Assoc, 85, 1137-1140.

Sparre, P. \& Venema, S.C. (1992). Introduction to tropical fish stock assessment. Part I. Manual FAO Fisheries Technical Paper 306/1 Rev.1. Danida FAO.Rome. Italy. 376 p.
Steel, R.D.G. \& Torrie, J.H. (1993). Prinsip dan prosedur statistika, suatu pendekatan biometrik (p. 748). Terjemahan B. Sumantri. Penerbit PT. Gramedia Pustaka Utama, Jakarta.

Suman, A. \& Boer, M. (2005). Ukuran pertama kali matang kelamin, musim pemijahan, dan parameter pertumbuhan udang dogol (Metapenaeus ensis de Haan) di perairan Cilacap. J.Lit.Perikan.Ind, 11(2), 65-71. http://dx.doi.org/ 10.15578/jppi.11.2.2005.69-74.

Tarp, G.T. \& Kailola, P.J. (1984). Trawled fishes of Southern Indonesia and Norhwestern Australia. ADAB-DFG-GTZ. Singapore. 406p.

Tiews, K. I. A., Ronquillo., \& P. Caces Borja.(1970). On the biology of roundscads (Decapterus bleeker) in the Philippines water. Proc.IPFC, 13(2), 82-106.

White, W. T., Last, P. R., Stevens, J. D., Yearsley, G. K., Fahmi., \& Dharmadi. (2006). Economicaly important sharks and rays of Indonesia. National Library of Australia Cataloging-in-Publication entry. Australia. 329p.

Whitney \& Crow. (2007). Reproductive biology of the tiger shark (Galeocerdo cuvier) in Hawai. Marine Biology, 151, 63-74.

Wintner S.P. \& Dudley, S.F.J. (2000). Age and growth estimates for tiger shark, Galeocerdo cuvier from the East Coast of South Afica. Mar. Freswater Res. 51, 43-53.

Wirsing, A.J., Heithaus, M.R., \& Dill, L.M. (2006). Tiger shark (Galeocerdo cuvier) abundance and growth in a subtropical embayment: evidence from 7 years of standardized fishing effort. Marine Biology. 149, 961-968. 